\title{
DC Conduction of Tsuga (Tsuga sieboldii CARR) in Cellulose I
}

\author{
Masae TAKAHASHI and Haruko TAKENAKA \\ Faculty of Home Economics, Japan Women's University, \\ 2-8-1 Mejirodai, Bunkyo-ku, Tokyo 112, Japan
}

(Received November 15, 1984)

\begin{abstract}
The absorption current and the steady-state current in a dc field have been measured in the temperature range from $140^{\circ} \mathrm{C}$ to $230^{\circ} \mathrm{C}$ for tsuga (Tsuga sieboldii CARR) of Cellulose I. The voltage-current characteristics at various temperatures follow the sine-hyperbolic law in the hopping model. The hopping distance is constant $\left(2.8 \times 10^{-6} \mathrm{~m}\right)$ at temperatures above about $140^{\circ} \mathrm{C}$. The absorption current characteristics are also explained by the hopping model. Drastic increase in the dc conductivity above about $150^{\circ} \mathrm{C}$ seems mainly due to an increase in the mobility.

KEY WORDS Cellulose I / Absorption Current / Steady-State Current / Hopping Model /
\end{abstract}

In a previous paper, ${ }^{1}$ it was found that the conductivity $v s$. temperature curve showed a break at about $150^{\circ} \mathrm{C}$ for Cellulose I (Cell I) and at about $80^{\circ} \mathrm{C}$ for Cellulose II (Cell II) in accord with the spacing $v s$. temperature curve. $^{2}$ These breaks are possibly associated with the second order transition at which the restricted motion of chain segments in the crystals begins to gain higher mobility. However, the conduction mechanism has not been discussed.

The present work has been undertaken to study dc conduction in detail and to clear the mechanism of dc conduction in cellulose, by measuring the absorption current and the steady-state current in a dc field in the temperature range from 140 to $230^{\circ} \mathrm{C}$ where the $\mathrm{dc}$ conductivity becomes relatively high.

\section{EXPERIMENTAL}

The samples of Cell I was prepared from soft wood tsuga (Tsuga sieboldii CARR), which showed clear X-ray meridional reflections. The crystallinities of the samples were almost the same.
The sample was parallelpiped in form $(10 \mathrm{~mm} \times 10 \mathrm{~mm} \times 15 \mathrm{~mm})$. The arrangement of electrodes and the method used for measuring the dc electrical current were the same as described in the previous paper. ${ }^{1}$ The maximum applied voltage was $540 \mathrm{~V}$. Prior to each measurement, the specimen was dried at $100^{\circ} \mathrm{C}$ for about $2 \mathrm{~h}$ under a pressure of $10^{-5}$ Torr.

\section{RESULTS AND DISCUSSION}

Figure 1 shows schematically the time characteristic of the current, after a dc voltage was applied at $t=0$. The dc current is denoted by $i_{\mathrm{d}}$, and the absorption current is denoted by $i_{\mathrm{a}}$. The temperature dependence of the dc electrical conductivity $\sigma$ is shown in Figure 2. As has been reported, ${ }^{1}$ a break is observed at temperature of about $150^{\circ} \mathrm{C}$ in both the fiber direction and the direction perpendicular to it (tangential direction).

To study quantitatively the dc conduction in Cell I, the voltage-current (steady-state) characteristics for two directions at various temperatures above $140^{\circ} \mathrm{C}$ were measured as 


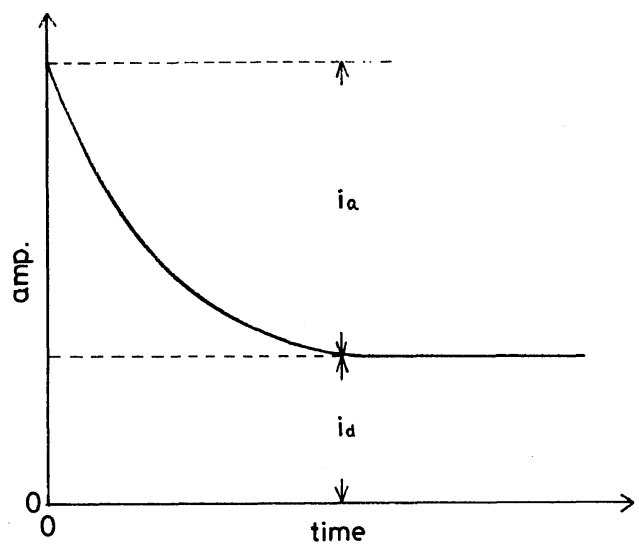

Figure 1. Schematic representation of current through sample.



Figure 2. Temperature dependence of the dc conductivity in two directions; $\|$, fiber direction; $\perp$, tangential direction.

shown in Figure 3(A) and (B). Below $140^{\circ} \mathrm{C}$, it was difficult to obtain the reliable voltagecurrent characteristics, because of lower conductivity. The solid lines show the calculated
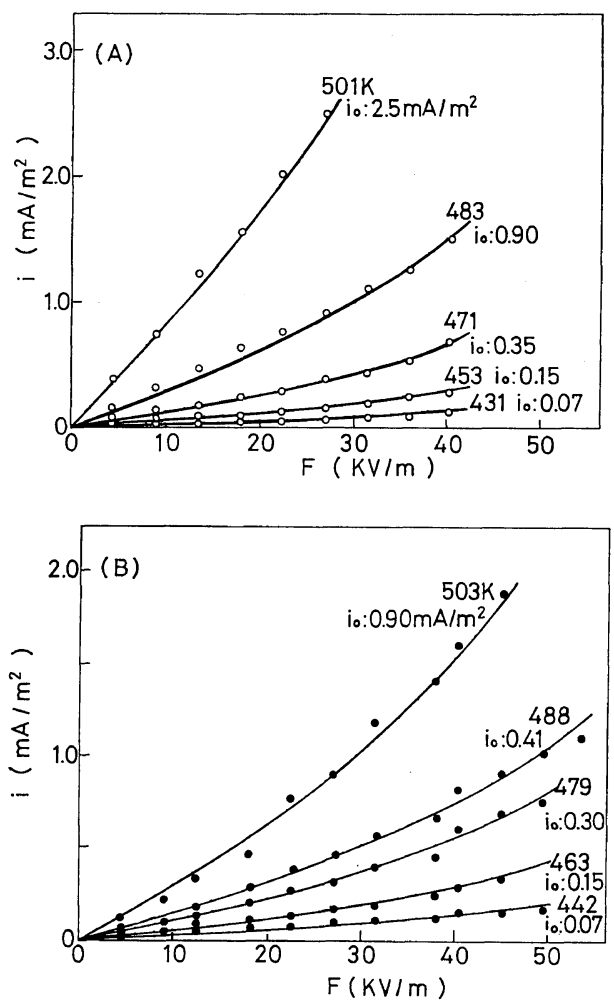

Figure 3. Voltage-current characteristics in two directions: (A), fiber direction; (B), tangential direction.

curves which are obtained by substituting the hopping distance $\lambda=2.8 \times 10^{-6} \mathrm{~m}$ and each initial current density $i_{0}$ into the sinehyperbolic equation in the hopping conduction model, ${ }^{3}$ i.e.,

$$
i=i_{0} \sinh (e \lambda F / 2 k T)
$$

Here $F$ is the electric field, $k$ is Boltzmann's constant and $T$ is the absolute temperature in $K$. As seen in the figures, the voltage-current characteristics can be well represented by the sine-hyperbolic equation and $\lambda$ is found to be constant in both directions over the temperature range higher than about $140^{\circ} \mathrm{C}$. Then, the possibility of the hopping conduction is expected. It has been stated by Murphy ${ }^{4}$ that the conduction in dry cellulose involves the tunneling of proton between equivalent sites, the one in the ion and the other in an adjacent 
neutral molecule. But the doubts about the correctness of this model above $40^{\circ} \mathrm{C}$ were pointed out by Tanaka, ${ }^{5}$ since the dissociation energy calculated by Murphy's equation ${ }^{4}$ was smaller than $1.72 \mathrm{eV}$ estimated for the activation energy of thermal decomposition. ${ }^{4}$ Our result $^{1}$ for activation energy is similar to Tanaka's result.

Figure 4 shows the initial current density $i_{0}$ in both directions plotted against $1 / T$. The apparent activation energies $\Delta H_{i_{0}}^{*}$ are $1.2 \mathrm{eV}$ in fiber direction and $1.0 \mathrm{eV}$ in tangential direction. It should be noticed that $\Delta H_{i_{0}}^{*}$ is almost equal, in both directions, to the apparent activation energy $\Delta H_{\sigma}^{*}$ reported. ${ }^{1}$

The solid curve in Figure 5 shows an example of the time evolution of absorption current at $187^{\circ} \mathrm{C}$ for the tangential direction, which can be divided into two exponential functions as represented by two dashed lines. The frequency dependence of dielectric loss $\varepsilon^{\prime \prime}$



Figure 4. Temperature dependence of the initial current density in two directions; $O$, fiber direction; tangential direction. can be calculated by substituting the slopes $\alpha_{i}$ $\left(\alpha_{1}=0.457 \mathrm{~s}^{-1}, \alpha_{2}=2.175 \mathrm{~s}^{-1}\right)$ and the current densities $\beta_{i}\left(\beta_{1}=50 \times 10^{-5} \mathrm{Am}^{-2}, \beta_{2}=\right.$ $81 \times 10^{-5} \mathrm{Am}^{-2}$ ) at $t=0$ into Whitehead's equation, ${ }^{6}$ i.e.,

$$
\varepsilon^{\prime \prime}(\omega)=\sum_{i} \omega \beta_{i} /\left(\omega^{2}+\alpha_{i}^{2}\right)
$$

where $\omega$ is the angular frequency. Figure 6 shows the angular frequency dependence of dielectric loss $\varepsilon^{\prime \prime}$ obtained at 187 and $139^{\circ} \mathrm{C}$ for the tangential direction. The relaxation fre-

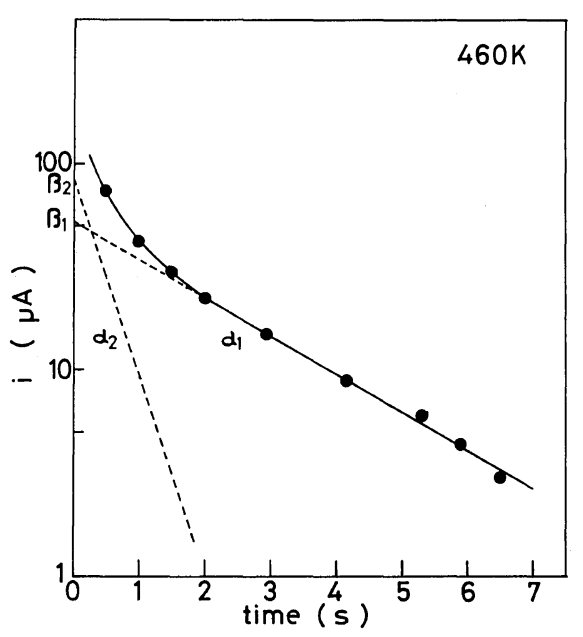

Figure 5. Time dependence of the absorption current in the tangential direction.

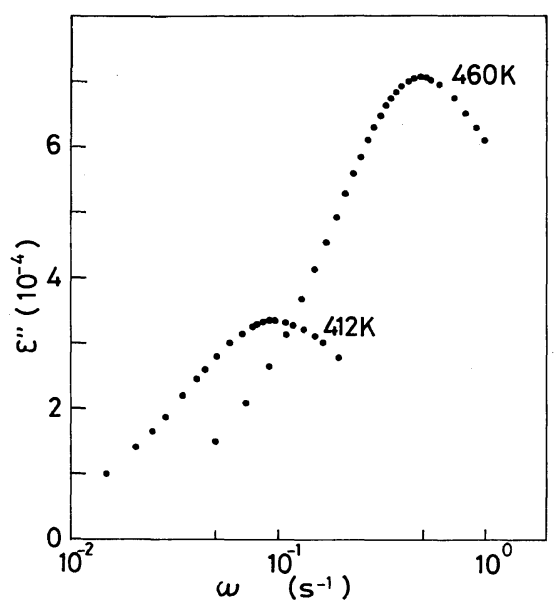

Figure 6. Angular frequency dependence of dielectric loss in the tangential direction. 


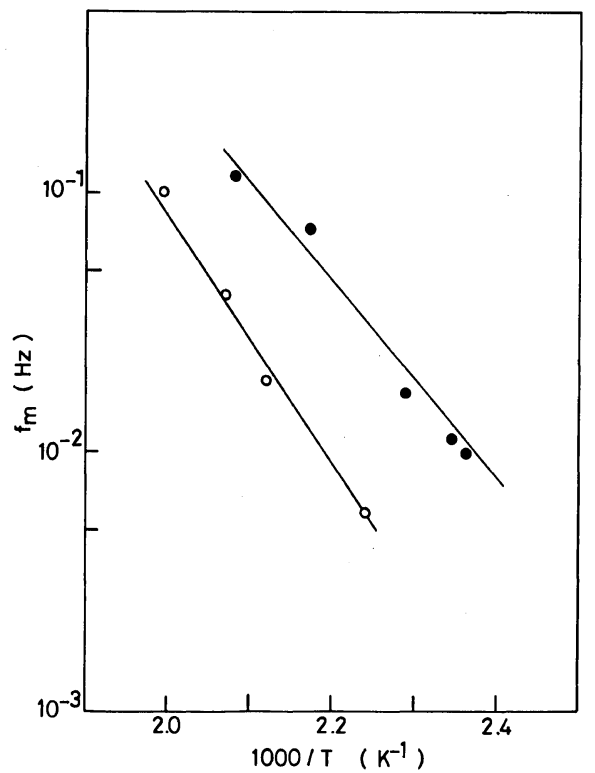

Figure 7. Temperature dependence of the relaxation frequency in two directions; $O$, fiber direction; tangential direction.

quency $f_{\mathrm{m}}$ at which $\varepsilon^{\prime \prime}$ has a maximum is plotted against $1 / T$ in Figure 7 . The apparent activation energies $\Delta H_{f_{\mathrm{m}}}^{*}$ are $0.93 \mathrm{eV}$ in the fiber direction and $0.75 \mathrm{eV}$ in the tangential direction, as estimated from Figure 7. The values correspond to the activation energies in connection with mobility $\mu$ in the hopping conduction model. The values are shown in Table I, together with $\Delta H_{i_{0}}^{*}$. The activation energy in carrier formation is estimated as the difference of $\Delta H_{i_{0}}^{*}-\Delta H_{f_{\mathrm{m}}}^{*}$. Then, the drastic increase in $\sigma$ would be mainly due to an increase in $\mu$.

Furthermore, it has been suggested? by the hopping conduction theory that $\sigma$ should be proportional to $2 \pi f_{\mathrm{m}} \varepsilon_{0} \Delta \varepsilon$, where $\Delta \varepsilon$ is the intensity of the dielectric absorption and $\varepsilon_{0}$ is the dielectric constant of vacuum. Figure 8 shows the relationship between $\log \sigma$ and $\log \left(2 \pi f_{\mathrm{m}} \varepsilon_{0} \Delta \varepsilon\right)$. The experimental points in both directions locate approximately between two straight lines, the dashed line drawn through the origin $(m=1)$ and the solid line drawn through the point of 1.9 times as the
Table I. Apparent activation energies

\begin{tabular}{|c|c|c|}
\hline & $\Delta H_{i_{0}}^{*}$ & $\Delta H_{f_{\mathrm{m}}}^{*}$ \\
\hline & $\mathrm{eV}$ & $\mathrm{eV}$ \\
\hline$\|^{\mathbf{a}}$ & 1.2 & 0.93 \\
\hline$\perp^{b}$ & 1.0 & 0.75 \\
\hline
\end{tabular}

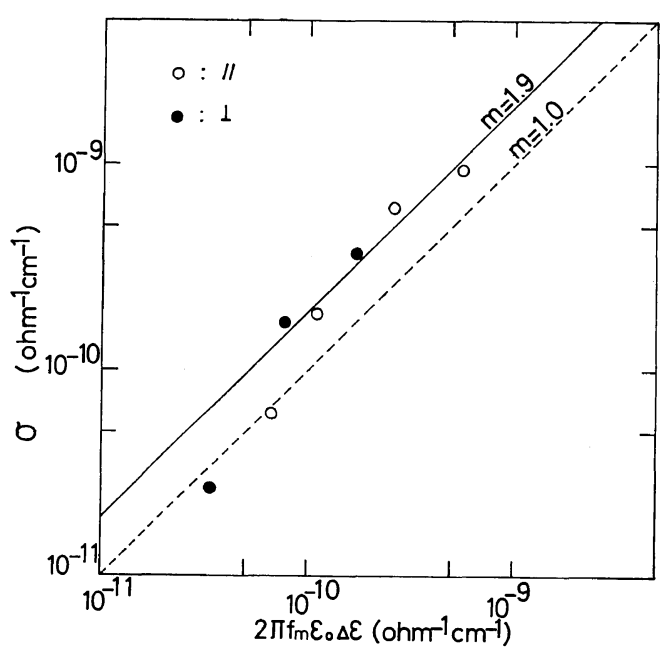

Figure 8. Relationship between $\sigma$ and $2 \pi f_{\mathrm{m}} \varepsilon_{0} \Delta \varepsilon$ in two directions; \|, fiber direction; $\perp$, tangential direction.

origin ( $m=1.9)$, with slope of 1 . Therefore it can be concluded that

$$
\sigma \simeq 2 \pi f_{\mathrm{m}} \varepsilon_{0} \Delta \varepsilon
$$

for Cell I. The result also supports the hopping conduction mechanism in cellulose. The carrier in cellulose may be ion such as proton or protonhole detected by Murphy. ${ }^{4}$

According to the hopping conduction theory, ${ }^{7}$ the mobility $\mu$ and the concentration $n$ of the charged particle are given by

$$
\begin{gathered}
\mu=2 \pi e f_{\mathrm{m}} \lambda^{2} / 12 k T \\
n=12 k T \varepsilon_{0} \Delta \varepsilon / e^{2} \lambda^{2}
\end{gathered}
$$

respectively, where $e$ is a protonic charge. The calculated values of $\mu$ and $n$ at $140-230^{\circ} \mathrm{C}$ are $\sim 10^{-12} \mathrm{~m}^{2} / \mathrm{Vs}$ and $\sim 10^{22} \mathrm{~m}^{-3}$. These values 
of $\mu$ and $n$ agree approximately with those obtained by Tanaka. ${ }^{5}$ The concentration $n_{0}$ of hydroxyls in cellulose is $1 \times 10^{29} \mathrm{~m}^{-3}$. Then, the ratio of $n$ to $n_{0}, n / n_{0}$, is $\sim 10^{-7}$. Therefore, the protons of a very small part of the hydroxyls contribute to the carrier.

\section{CONCLUSION}

The voltage-current characteristics for two directions of Cell I at various temperatures are explained in terms of the sine-hyperbolic law in the hopping model. The hopping distance is constant $\left(2.8 \times 10^{-6} \mathrm{~m}\right)$ above about $140^{\circ} \mathrm{C}$ in both directions. Absorption currrent characteristics are also explained by the hopping model.

Drastic increase in $\sigma$ above about $150^{\circ} \mathrm{C}$ may be mainly due to an increase in $\mu$. The ratio of carrier density to the concentration of hydroxyls in cellulose is $\sim 10^{-7}$.

Acknowledgement. The authors wish to express their appreciation to Dr. P. H. Kim for his valuable comments and guidance.

\section{REFERENCES}

1. M. Takahashi and H. Takenaka, Polym. J., 15, 625 (1983).

2. M. Takahashi and H. Takenaka, Polym. J., 14, 675 (1982).

3. L. E. Amborski, J. Polym. Sci., 62, 331 (1962).

4. E. J. Murphy, Can. J. Phys., 41, 1022 (1963).

5. T. Tanaka, Central Research Institute of Electric Power Industry Techn. Rept., No. 68081 (1968).

6. S. Saito, "Kobunshi Jikken Gaku," Vol. 12, The Society of Polymer Science, Japan, Ed., Kyoritsu Publishing Co., Ltd., Tokyo, 1984, Section 5.1.7.

7. S. Saito, S. Hirota, and H. Sasabe, Rep. Prog. Polym. Phys., Jpn., 17, 399 (1974). 